\title{
REVIEW
}

\section{Review of Strategies For Measuring Advances In Student Learning: A Synopsis For Authors and Reviewers}

\author{
Ashley N. Castleberry, PharmD, MEd, ${ }^{a}$ Melissa S. Medina, EdD, ${ }^{\text {bee }}$ Adam Persky, PhD, ${ }^{\text {cee }}$ Lauren S. \\ Schlesselman, MA Ed Psych, PharmD ${ }^{\text {d,e }}$ \\ ${ }^{\text {a }}$ University of Texas at Austin, College of Pharmacy, Austin, Texas \\ ${ }^{\mathrm{b}}$ University of Oklahoma, Health Sciences Center College of Pharmacy, Oklahoma City, Oklahoma \\ ${ }^{\mathrm{c}}$ University of North Carolina, Eshelman School of Pharmacy, Chapel Hill, North Carolina \\ ${ }^{\mathrm{d}}$ University of Connecticut, Center for Excellence in Teaching and Learning, Storrs, Connecticut \\ ${ }^{\mathrm{e}}$ Associate Editor, American Journal of Pharmaceutical Education, Arlington, Virginia
}

Corresponding Author: Lauren S. Schlesselman, University of Connecticut Center for Excellence in Teaching and Learning, 368 Fairfield Way, Unit 4001, Storrs, CT 06269. Tel: 860-486-3402. Email: laurens@ uconn.edu

Submitted April 28, 2021; accepted August 3, 2021; ePublished August 2021

\begin{abstract}
Objective. To provide guidance on how to design educational research studies to better capture evidence of student learning

Findings. A wide variety of assessment tools are available to measure student learning associated with educational innovations. Each assessment tool is associated with different advantages and disadvantages that must be weighed to determine appropriateness for each situation. Additionally, the educational research design must be aligned with the intent of the study in order to strengthen the impact of the study.

Summary. By selecting research methods aligned with Kirkpatrick's levels of training evaluation, researchers can create stronger evidence of student learning when evaluating the effectiveness of teaching innovations.

Keywords: student learning, educational research, assessment of learning
\end{abstract}

\section{INTRODUCTION}

Researchers conduct educational research to inform our community on how to improve learning of the future generations. The more instructors understand about student learning, the more they can do to improve it. With that charge, we hope to make evidence-based decisions on how to get students to learn the desired knowledge and skills. Ultimately, we hope these knowledge and skills translate to workplace behaviors and positive patient outcomes. However, our ability to make decisions on what is best and in what context depends on our ability to think critically and to have quality evidence to think about. It is the latter that concerns the educational community-do we have quality evidence and if not, how do we generate it? The objective of this review article is to provide guidance on how to design educational research studies to better capture evidence of student learning.

To frame this article, we will start with a discussion of taxonomies for training and/or evaluating the level of evidence in the scholarship of teaching and learning (SOTL) or an educational research study. One should keep in mind that evaluating the level of evidence in an educational research study is akin to assessing evidence in clinical practice. In clinical practice, opinions of authorities or experts are considered the lowest evidence and the systematic reviews and meta-analysis of relevant randomized controlled trials are considered the highest. ${ }^{1}$ For instance, if we want to answer a clinical question about the best therapy, we would look towards randomized controlled trials, meta-analysis and to a lesser extent cohort studies, case-control studies and cases series, remembering that the outcomes are related to the actual goals of the intervention.

One popular taxonomy is Kirkpatrick's levels of training evaluation. At its base are feelings or perceptions. This level captures how the learner feels or perceives the training has or has not benefited them. This is considered low level evidence because perceptions are biased and in general, humans are not great judges of what they know or can do. ${ }^{2,3}$ For example, the ease of fluency bias states that people feel that things that are learned easily are well learned or things that come to mind quickly are correct. ${ }^{4-5}$ This is a bias, just because something seems easy, does not mean it is learned and answers that come to mind first, are not necessarily the correct ones. ${ }^{6}$ The main purpose of the perceptions level is to obtain positive comments from the learners so they would attend future training programs and negative comments to improve the training program. ${ }^{7}$ The comments themselves do not guarantee learning. 
Above the level of perception is knowledge and conceptual knowledge which includes the more traditional paper and pen facts. This assessment still has some subjectivity as the trainer selects items to be tested but less subjective than perceptions of trainees. This level of assessment establishes that students can recall facts and perform skills when prompted. It is these facts and skills that are required to enact behaviors. As stated in some of the original work by Kirkpatrick, without learning, as measured by knowledge acquisition, no behavioral change will occur. ${ }^{7}$

In fact, behavioral change is the third level of the taxonomy. In this level, learners are asked to perform behaviors they were trained to do - that is, does the learners job performance become better as a result? Can they execute the skill? Can they teach others? The ability to perform a skill and to teach others, such as a patient, requires a higher level of understanding than a simple knowledge test. And ultimately, the goal of training is to improve student outcomes and organizational performance, along with patient outcomes in the case of health education; thus, the third level is quite important.

The last level is results. While behaviors are great, we want to know if the behaviors translate to positive results, just like we hope innovation leads to better outcomes and we are not innovating for innovation sake. So, the results of the behavior are the highest level of training outcomes. The hard part is determining the outcome. For a University, for example, is the outcome improved graduation rates of learners? Number of acceptances to post-graduate training or jobs? Decreased costs of training to the learner? One individual makes a fifth level of Kirkpatrick's taxonomy and this last level is the return on investment or cost-effectiveness. ${ }^{7}$ That is, does the training cause results and at what cost? This is an important issue in educational research-what strategies result in better learning, in what contexts and at what cost?

While this model can be useful for evaluating the level of evidence used in a research study, Kirkpatrick's model has its limitations. The first is its hierarchical nature; higher levels are more important. This hierarchy can be problematic because all levels are required for decision making. If a training program leads to behavior change but the learners perceive it poorly, that may impact what changes are required. Another limitation is the intercorrelations between levels; the knowledge needed for behavioral change is also needed for results. There are no guarantees that improved perceptions lead to more knowledge or that more knowledge leads to behavioral change or that behavioral change leads to results. The Kirkpatrick model can still be a useful framework for evaluating levels of evidence if researchers address these limitations. However, several other models have been developed that researchers can use such as the Input, Process, Output (IPO) Model, Brinkerhoff's six-stage model, Context, Input, Process and Product (CIPP) Model, Context Input Reaction Outcome (CIRO) Model, and Kaufman and Keller's five levels of training. ${ }^{7-9}$ Overall, whatever model(s) a researcher selects to evaluate their evidence, they should remember that the goal of educational research is to find what benefits student learning and in what contexts. Thus, we need to establish that learning has occurred and that it can be linked to an intervention. To guide researchers in this evaluation process, the remainder of this review will present strategies faculty can use to assess student learning through the lens of various models including Kirkpatrick's model since it offers clear steps to follow in order to gain insights about learning outcomes. Faculty can then use this guidance to better evaluate and document student changes. If disseminated, this will lead to the improved quality of educational literature.

\section{Assessment Tools}

Many assessment tools/measures are used to assess educational interventions in pharmacy education. These can be categorized based on Kirkpatrick's taxonomy of training evaluation. The first level, Reaction, includes measures such as learner perceptions of confidence or satisfaction in the experience. These are commonly evaluated with selfassessments or course evaluations. The second level, Learning, is often assessed using tools like quizzes (planned or surprise), examinations, course grades, and even the Pharmacy Curriculum Outcomes Assessment (PCOA). Behaviors, level three, can be evaluated on Objective Structured Clinical Examinations (OSCEs) and Experiential Learning-both Introductory Pharmacy Practice Experiences (IPPEs) and Advanced Pharmacy Practice Experiences (APPEs). The highest level, Results, can be captured through Entrustable Professional Activities, North American Pharmacist Licensure Examination (NAPLEX) and Multistate Pharmacy Jurisprudence Examination (MPJE) success, and performance in professional practice after graduation. Each measure has benefits and limitations that the researchers must carefully consider (Tables 1 and 2).

\section{Research Design}

The research question should be meaningful, clear, and relevant to the advancement of pharmacy education and educational theory. The nature of the research question will determine the best approach to utilize. Cook et $\mathrm{al}^{10} \mathrm{developed}$ a hierarchy for medical education research based on the intent of the study. The three main categories are description, justification, and clarification. The lowest level, description, refers to studies that present an innovation for which there is 
no available comparison. Justification, the middle category, involves studies comparing the effectiveness of different educational interventions, answering the question as to which is better. Clarification, the top category, offers advancement for the educational literature because these studies answer the questions of how the intervention works and why it works. Strongly aligning the educational research design with the intent of the study strengthens the impact of the findings for others in the Academy.

\section{Define Learning Objectives}

Most educational research evaluates the impact of an intervention on student learning. Although research can evaluate why and how this impact occurred through design-based research, to date this is only undertaken in a limited number of studies.

A well-designed research project should model the backward design of learning model. As outlined by Wiggins and McTighe ${ }^{11}$, backward design of learning experiences starts by identifying objectives; what students should know, be able to do, or believe by the end of the learning cycle. This is followed by creation of the assessment to measure changes in what students know, can do, or believe. The final step is planning the sequence of lessons and activities that will prepare students to successfully complete the planned assessment. In contrast, weaker research projects (and educational experiences) identify a topic or content that needs to be covered, plan lessons and activities to teach that topic, then create an assessment to measure the learning or simply evaluate student perception of the experience or of learning.

Evaluation of impact on knowledge, skills, and attitude provides researchers the ability to analyze at Kirkpatrick's second level and above. But, in order to evaluate the impact on achievement of learning objectives, researchers must first define the measurable learning objectives for the course or activity. There are several tiered taxonomies of learning. (Table 3)

Bloom's taxonomy ${ }^{12}$ of educational objectives remains the most widely known taxonomy when developing learning objectives. This hierarchical ordering of cognitive learning consists of six levels ranging from remembering to creating with the upper three levels requiring learners to utilize higher order thinking skills. At the lowest level of the taxonomy (remembering), learners are recognizing and recalling facts. As they move up the hierarchy, learners start to understand the meaning of the facts (understanding) and to apply the facts, rules, concepts, and ideas (applying). From here, learners start to be able to break down information into component parts (analyzing), judge the value of information or ideas (evaluating), and finally combine parts to make a new whole (creating).

Fink's taxonomy ${ }^{13}$ of significant learning utilizes an interactive, rather than hierarchical approach to learning. Therefore, each type of learning can stimulate other types of learning to occur. The six levels of Fink's taxonomy are foundational knowledge, application, integration, human dimension, caring, and learning how to learn. Foundational knowledge, serving as the base of learning, involves the learner's ability to remember and understand information. The application of knowledge occurs when learners develop critical, creative, and practice thinking abilities. Integration represents the making of connections between knowledge, ideas, perspectives, learning experiences, and from different realms of life. Human dimensions of learning involve learning about self (personal) and others (social), particularly how to use reflection and feedback to identify areas of strength or for improvement along with how to interact with others. Caring requires the development of feelings about something new or caring in a new way. Finally, learning how to learn involves becoming a better student and becoming a self-directed learner in order for learning to continue beyond the learning experience.

When developing learning objectives related to the affective domain, Krathwohl's ${ }^{14}$ taxonomy is one of the best known. The 5-tiered taxonomy is ordered according to the principle of internalization, a process in which a learner's affect ranges from general awareness to acting consistently in accordance with a set of values. At the lowest level (receiving), learners become aware of or sensitive to the existence of ideas and phenomena, along with being willing to tolerate them. At the responding level, learners go beyond attending to a phenomenon to react to it in some way, including questioning new ideals, concepts, and models to fully understand them. When learners reach the valuing level, they are concerned with the worth or value they attach to a phenomenon, behavior, or object, ranging from simple acceptance of a value to a more complex level of commitment. The organization level is concerned with bringing together different values into a harmonious and internally consistent belief or philosophy. Finally, in characterization by a value or value set, the learner acts consistently within the bounds of their internalized value system.

While psychomotor learning objectives are less common in pharmacy education, multiple taxonomies are also available for instructors looking to create psychomotor objectives. Two commonly utilized psychomotor taxonomies are Dave ${ }^{15}$ and Simpson ${ }^{16}$. Dave's is a simple five-tiered taxonomy addressing competence in performing skills ranging from imitation to naturalization, while Simpson's taxonomy focuses on mastery progression from observation to invention. 


\section{Match the Tool and Study Outcomes to The Learning Objectives}

Just as the assessment of learning in the class must be matched with the intended learning objectives, so must the tool used in the research project be matched with the learning objectives when evaluating if the educational intervention impacted learning. A study by FitzPatrick et al. ${ }^{17}$ reported poor content validity of assessments due to mismatching of learning objectives and assessments or insufficient assessment tasks to adequately assess student learning. In order to sufficiently assess learning, each objective should have at least 5-6 tasks aligned to it. ${ }^{18}$

A handful of processes are available to determine alignment between learning objectives or standards and assessments, including the Webb alignment process. ${ }^{19}$ The Webb process compares standards and assessments on depthof-knowledge consistency, categorical concurrence, range-of-knowledge consistency, and balance of representation. While this process may be more in depth than most educational research projects warrant, it does provide a solid framework. Assessment tasks should not only cover the topic but should be as demanding cognitively as what students are expected to know and as stated in the learning objectives or as required in practice. ${ }^{20}$

Each item in an assessment tool should be clearly aligned with one or more objectives with this alignment shared in the manuscript. Multiple assessment items should be aligned to each learning objective. To demonstrate a change in knowledge, skills, and attitudes, researchers should provide data on the change in learning for each of those learning objectives.

\section{Avoid Perceptions As Only Measure}

In the classroom, student perceptions of learning or of the educational experience are not the measure utilized to evaluate their knowledge, skills, or attitudes. Similarly, student perceptions should not be the only measure utilized to evaluate the success of a learning intervention. As outlined above, reactions, such as satisfaction, and change in attitude are Kirkpatrick's lowest levels for analyzing and evaluating the results of an educational experience.

In general, individuals tend to be overconfident when evaluating their own performance as demonstrated by Dunning and Kruger ${ }^{21}$ who found that less competent individuals are unable to recognize their own incompetence, leading them to overrate their ability due to a lack of metacognition, referred to as illusory superiority. Pennycock ${ }^{22}$ and colleagues reported individuals with the greatest number of errors on a cognitive reflection test overestimated their performance by a factor of more than three. In an evaluation of metacognitive accuracy relative to professional skills, Zell and Krizan ${ }^{23}$ found a weak correlation between perceived ability and actual ability. A 2020 study ${ }^{24}$ found a lack of correlation between student perceived achievement and change in ability.

Despite verification of the Dunning-Kruger effect, many educational researchers' base claims of effectiveness of an educational intervention solely on student perceptions of learning or attitudes. To better demonstrate achievement, researchers should triangulate using other measures of achievement.

\section{Pre-Post Assessments}

Pre-post assessments are designed to assess learning over a pre-determined period of time before and after the learning intervention. The pre-test component serves as a baseline assessment of knowledge and skills, while the post-test measures progress due to the educational experience.

The pre-assessment, or background knowledge probe as described by Angelo and Cross ${ }^{25}$, provides the instructor with insight into student knowledge retained from previous courses or experiences. The results of the pre-test serve two functions. The first is allowing instructors to evaluate if students possess the necessary pre-requisite knowledge, thereby allowing the instructor to adjust the educational intervention to account for this. The second is reducing the assumption that achievement post-educational intervention is solely due to the intervention. To achieve these functions, the pre-test should contain questions pertaining to essential pre-requisite knowledge in addition to questions aligned with the knowledge and skills expected to be gained during the educational intervention.

As with all assessments, items on pre-post assessments should be aligned to the learning objectives. This alignment should be made clear in the manuscript, so readers know how much of an improvement occurred in response to the educational intervention for each learning objective.

The use of pre-post assessments allows for a variety of in-depth statistical analyses beyond change in grade. In addition to paired t-tests, researchers may consider use of Rasch model fit, test reliability, item response analysis, mean person ability, and other analyses.

A pre-post design can still be limited in providing an accurate understanding of whether the change observed is only attributable to the intervention or how the impact was achieved. They also do not demonstrate sustained change over time or if students retain over time the outcomes they gained. 


\section{Control Groups}

Comparison of outcomes for two different groups is another approach for determining the success of an educational intervention. A control group provides an estimate of what the experimental group would have learned or achieved had it not received the educational intervention. The control group ensures the internal validity of the research. When using a control group, the researcher should ensure the same educational outcomes are intended and measured.

Control groups comparisons may be equivalent or non-equivalent groups designs. For an equivalent group study, subjects are randomly assigned to either the control group or the experimental group. Each group, chosen and assigned at random, is presented with either the new educational intervention or the standard experience. In such a design, a randomly selected group of students in the current class are assigned to continue to receive whatever educational experience was provided previously or to receive no training. For this design, if the students in the control group are not receiving any educational experience as part of the study, it is important to provide them with training after the experiment to ensure they are not lacking knowledge or skills essential to pharmacy practice.

For post-test nonequivalent groups design, one group is exposed to the educational intervention while the other is not exposed. In pharmacy education research, this is most often seen when researchers compare results of students in a previous year to the current year. Because the students in the previous year were not randomly assigned to this control group, researchers cannot assume they are equivalent to the current class. Researchers can attempt to match students in the control group with students in the educational intervention group but ensuring students are well-matched on all variables poses significant challenges due to confounding variables.

Utilizing cohorts within the same class can lead to IRB challenges if the control group is not provided with an experience that is superior or is not taught a new topic. To overcome this, researchers can include in the study design and IRB submission a plan to provide the control group with the educational intervention or topic after the study is completed. This can lead to additional learning time for students and uneven assessment requirements, along with teaching challenges. Due to these and other challenges this study design of using a control group within the same class is less frequently utilized.

\section{Long-Term Retention Versus Short-Term Performance}

Research on the long-term impact on behavior or patient care provides evaluation at the third and fourth levels of Kirkpatrick's model when a long-term evaluation of impact is added to the research design. In the rush to publish, many researchers do not design projects evaluating the long-term impact of an educational intervention. Yet, this approach can demonstrate a deeper impact of an educational intervention. This design can assess, not only the impact over time, but also the relevance to practice by measuring how this learning translates into pharmacist behavior and patient outcomes. Evaluation at these levels can involve repeated assessment at later points in the curriculum, evaluation of behavior during APPEs, or even evaluation post-graduation.

\section{Mixed Methods}

Mixed method research involves a combination of qualitative and quantitative dimensions "for the broad purposes of breadth and depth of understanding and corroboration." ${ }^{26}$ The goal of mixed methods is to expand the knowledge obtained and validate the findings. To achieve multiple validities legitimation ${ }^{27}$, the study must meet validation requirements for all aspects of the study. According to Bryman $(2006)^{28}$, six specific purposes exist for mixed methods research: credibility (to enhance the integrity of the findings); context (using qualitative research providing contextual understanding coupled with generalizability, external validation, or broad relationships among variables); illustration (using qualitative data to illustrate quantitative findings); utility (to improve the usefulness of findings); confirm and discover (to generate hypotheses using qualitative research that is then tested with quantitative research); and diversity of views (combining researchers' and participants' perspectives). With true mixed methods, the study must have at least one point of integration. This integration occurs by merging the two data sets, connecting analyses of one set of data to the other, embedding one form of data within the larger design; and using a framework to bind the data sets. ${ }^{29}$ (See Table 4 for the four types of mixed methods designs.)

The differences between quantitative and qualitative measures extend beyond the presence or absence of numbers. Quantitative research aims to answer questions of causality. In contrast, qualitative research focuses on answering the whys and hows ${ }^{30}$ Although qualitative research often involves smaller samples sizes, the concept of saturation is used to determine data collection completeness. Data saturation is a measure of rigor that is used to estimate qualitative sample sizes and is a criterion for discontinuing data collection (ie, how many qualitative interviews are enough so that no new data are found?). ${ }^{31,32}$ 


\section{Triangulate}

Triangulation is sometimes used to refer to all instances in which two or more research methods are utilized, but it is also a mixed method approach referring to the use of more than one approach to enhancing confidence in the findings and adding to the richness and complexity of the inquiry. The concept was first proposed by Campbell and Fiske (1959) ${ }^{33}$ who advocated for the use of multiple measures to determine the extent to which different measures converged. Denzin and Lincoln (1994) ${ }^{34}$ argued that triangulation added rigor, breadth, and depth to an investigation. Denzin ${ }^{34}$ identified four basic types of triangulation: data, investigator, theory, and methodological. Data triangulation entails gathering data at different times but also with a variety of groups, while theoretical refers to the use of more than one theoretical position in interpreting data. Methodological triangulation refers to the use of more than one method for gathering data; investigator triangulation entails the use of more than one researcher to gather and interpret data.

\section{SUMMARY}

By selecting research methods aligned with Kirkpatrick's levels of training evaluation, researchers can create stronger evidence of student learning when evaluating the effectiveness of teaching innovations. When designing or evaluating an educational research study, authors and reviewers should clearly define the learning outcome and ensure the tools and study outcomes match these learning objectives. Researchers should also move past gathering perception data alone and design rigorous methods to assess long-term retention of learning. They should consider mixed method approaches when appropriate and triangulate data from multiple sources when drawing conclusions. By carefully designing educational research projects, faculty can improve the quality of evidence for student learning.

\section{REFERENCES}

1. Council. NHaMR. NHMRC Levels of Evidence and Grades for Recommendations for Developers of Clinical Practice Guidelines: National Health and Medical Research Council.; 2009.

2. Dunning D, Heath C, Suls JM. Flawed Self-Assessment: Implications for Health, Education, and the Workplace. Psych Sci Public Interest. 2004;5(3):69-106.

3. Woolliscroft JO, Woolliscroft JO, Tenhaken J, et al. Medical students' clinical self-assessments: comparisons with external measures of performance and the students' self-assessments of overall performance and effort. Acad Med. 1993;68(4):285-94.

4. Reber R, Greifeneder R. Processing Fluency in Education: How Metacognitive Feelings Shape Learning, Belief Formation, and Affect. Educ Psych. 2017;52(2):84-103.

5. Wänke M, Hansen J. Relative Processing Fluency. Curr Dir Psych Sci. 2015;24(3):195-9.

6. Benjamin AS, Bjork RA, Schwartz BL. The Mismeasure of Memory: When Retrieval Fluency Is Misleading as a Metamnemonic Index. J Exp Psych. 1998;127(1):55-68.

7. Reio TG, Rocco TS, Smith DH, Chang E. A Critique of Kirkpatrick's Evaluation Model. New Horiz Adult Educ Hum Resourc Develop. 2017;29(2):35-53.

8. Botek M. Comparison of education evaluation models. Qualit Access Success. 2018;19(165):63-7.

9. Passmore J, Velez MJ. Training Evaluation. In: Kraiger K, Passmore J, Santos NRd, Malvezzi S, eds. Chichester, UK: John Wiley \& Sons, Ltd; 2014:136-53.

10. Cook DA, Beckman TJ, Bordage G. Quality of reporting of experimental studies in medical education: a systematic review. Med Educ. 2007;41(8):737-45.

11. Wiggins GP, McTighe J. Understanding by design. Expanded 2nd ed. Alexandria, VA: Association for Supervision and Curriculum Development; 2005.

12. Anderson LW, Krathwohl DR. A taxonomy for learning, teaching, and assessing : a revision of Bloom's taxonomy of educational objectives. Complete ed. New York: Longman; 2001.

13. Fink LD. Creating significant learning experiences : an integrated approach to designing college courses. Revised and updated edition. ed. San Francisco: Jossey-Bass; 2013.

14. Krathwohl DR, Bloom BS, Masia BB. Taxonomy of educational objectives: Handbook II: Affective domain. New York: David McCay, Co; 1964.

15. Dave RH. Developing and Writing Behavioral Objectives. In: Armstrong RJE, ed: Educational Innovaters Press; 1970.

16. Simpson EJ. The classification of educational objectives in the psychomotor domain. . Washington DC: Gryphon House; 1972.

17. FitzPatrick B, Hawboldt J, Doyle D, Genge T. Alignment of learning objectives and assessments in therapeutics courses to foster higher-order thinking. Am J Pharm Educ. 2015;79(1):1-8. 
18. Frisbie DA. Checking the alignment of an assessment tool and a set of content standards. Iowa Technical Adequacy Project (ITAP). Iowa City: University of Iowa; 2003.

19. Webb NL. Criteria for alignment of expectations and assessments in mathematics and science education (Council of Chief State School Officers and National Institute for Science Education Research Monograph No. 6. Madison: University of Wisconsin, Wisconsin Center for Education Research; 1997.

20. Webb NL. Issues related to judging the alignment of curriculum standards and assessments. Appl Measure Educ. 2007;20(1):7-25.

21. Kruger J, Dunning D. Unskilled and Unaware of It: How Difficulties in Recognizing One's Own Incompetence Lead to Inflated Self-Assessments. J Personality Soc Psych. 1999;77(6):1121-34.

22. Pennycook G, Ross RM, Koehler DJ, Fugelsang JA. Dunning-Kruger effects in reasoning: Theoretical implications of the failure to recognize incompetence. Psych Bull Rev. 2017;24(6):1774-84.

23. Zell E, Krizan Z. Do People Have Insight Into Their Abilities? A Metasynthesis. Persp Psych Sci. 2014;9(2):11125.

24. Persky AM, Lee E, Schlesselman LS. Perception of Learning Versus Performance as Outcome Measures of Educational Research. Am J Pharm Educ. 2020;84(7):993-1000.

25. Angelo TA, Cross KP. Classroom assessment techniques : a handbook for college teachers. 2nd ed. San Francisco: Jossey-Bass Publishers; 1993.

26. Johnson RB, Onwuegbuzie AJ, Turner LA. Toward a Definition of Mixed Methods Research. J Mix Method Res. 2007;1(2):112-33.

27. Johnson B, Christensen LB. Educational research : quantitative, qualitative, and mixed approaches. Sixth edition. ed. Thousand Oaks, California: SAGE Publications, Inc.; 2017.

28. Bryman A. Integrating quantitative and qualitative research: how is it done? Qualit Res. 2006;6(1):97-113.

29. Creswell JW, Plano Clark VL. Designing and conducting mixed methods research. 2nd ed. Los Angeles: SAGE Publications; 2011.

30. Kuper A, Reeves S, Levinson W. An introduction to reading and appraising qualitative research. Br Med J. 2008;337(aug07 3):a288-a.

31. Guest G, Namey E, Chen M. A simple method to assess and report thematic saturation in qualitative research. PLoS One. 2020;15(5):e0232076-e.

32. Saunders B, Saunders B, Sim J, et al. Saturation in qualitative research: exploring its conceptualization and operationalization. Qual Quant. 2018;52(4):1893-907.

33. Campbell DT, Fiske D. Convergent and discriminate validation by the multitrait-multimethod matrix. Psych Bull. 1959;56:81-105.

34. Denzin NK, Lincoln YS. Introduction: Entering the Field of Qualitative Research; 1994:1-17.

35. Medina MS, Castleberry AN, Persky AM. Strategies for Improving Learner Metacognition in Health Professional Education. Am J Pharm Educ. 2017;81(4):78-.

36. Schneider EF, Castleberry AN, Vuk J, Stowe CD. Pharmacy students' ability to think about thinking. Am J Pharm Educ. 2014;78(8):148-.

37. Medina MS, Schwier NC, Miller JL, Miller MM, Skrepnek GH. Career Skills Assessment in a Doctor of Pharmacy Curriculum. Am J Pharm Educ. 2018;82(7):6300-.

38. Medina MS, Autry MT, Draugalis JR, Neely SB, Shreffler MR, Hausner SB. Longitudinal Outcomes of an Elective Academic and Administrative Advanced Pharmacy Practice Experience. Am J Pharm Educ. 2019;83(3):6587-392.

39. Medina MS, Smith WT, Kolluru S, Sheaffer EA, DiVall M. A Review of Strategies for Designing, Administering, and Using Student Ratings of Instruction. Am J Pharm Educ. 2019;83(5):7177-764.

40. Persky AM, Wells MA, Sanders KA, Fiordalisi J, Downey C, Anksorus HN. Improving dental students' longTerm retention of pharmacy knowledge with "medication minutes". J Dent Educ. 2017;81(9):1077-84.

41. Terenyi J, Anksorus H, Persky AM. Optimizing the Spacing of Retrieval Practice to Improve Pharmacy Students' Learning of Drug Names. Am J Pharm Educ. 2019;83(6):1213-9.

42. Medina MS. Relationship between case question prompt format and the quality of responses. Am J Pharm Educ. 2010;74(2):29-.

43. Farland MZ, Sicat BL, Franks AS, Pater KS, Medina MS, Persky AM. Best practices for implementing teambased learning in pharmacy education. Am J Pharm Educ. 2013;77(8):177-.

44. Medina MS, Conway SE, Davis-Maxwell TS, Webb R. The impact of problem-solving feedback on team-based learning case responses. Am J Pharm Educ. 2013;77(9):189-. 
45. Letassy NA, Fugate SE, Medina MS, Stroup JS, Britton ML. Using team-based learning in an endocrine module taught across two campuses. Am J Pharm Educ. 2008;72(5):103-.

46. Medina MS, Neely S, Draugalis JR. Predicting Pharmacy Curriculum Outcomes Assessment Performance Using Admissions, Curricular, Demographics, and Preparation Data. Am J Pharm Educ. 2019;83(10):2184-93.

47. Rudolph M, Gortney JS, Brownfield A, et al. Student perceptions of the utility of the Pharmacy Curriculum Outcomes Assessment. Curr Pharm Teach Learn. 2020;12(3):255-64.

48. Sturpe DA. Objective structured clinical examinations in doctor of pharmacy programs in the United States. Am J Pharm Educ. 2010;74(8):148-.

49. Heldenbrand SD, Dayer LE, Martin BC, et al. APPE Evaluations are Positively Associated with MMI, Prepharmacy GPA and Pharmacy GPA. Am J Pharm Educ. 2018;82(7):818-25.

50. Pittenger AL, Gleason BL, Haines ST, Neely S, Medina MS. Pharmacy Student Perceptions of the Entrustable Professional Activities. Am J Pharm Educ. 2019;83(9):1974-82.

51. Williams JS, Spivey CA, Hagemann TM, Phelps SJ, Chisholm-Burns M. Impact of Pharmacy School Characteristics on NAPLEX First-time Pass Rates. Am J Pharm Educ. 2019;83(6):1366-72.

52. Davis DA, Mazmanian PE, Fordis M, Van Harrison R, Thorpe KE, Perrier L. Accuracy of Physician Selfassessment Compared With Observed Measures of Competence: A Systematic Review. JAMA. 2006;296(9):1094-102.

53. Duffy FD, Holmboe ES. Self-assessment in Lifelong Learning and Improving Performance in Practice: Physician Know Thyself. JAMA. 2006;296(9):1137-9.

54. Peeters MJ, Martin BA. Validation of learning assessments: A primer. Curr Pharm Teach Learn. 2017;9(5):92533.

55. Medina MS. Assessing student performance during experiential rotations. Am J Health Sys Pharm. 2008;65(16):1502-6. 
Table 1. Benefits and Limitations of Assessment Tools/Measures Categorized Along Kirkpatrick's Four Levels of Evidence (Reaction, Learning, Behavior, Results)

\begin{tabular}{lll}
\hline Measure Benefits Limitations & L
\end{tabular}

Reaction

Self-Assessment ${ }^{34-36}$

Perceptions, Confidence

Satisfaction ${ }^{38}$

Course Evaluations ${ }^{39}$

Learning

Quiz, Planned ${ }^{37}$
Student reflection required by ACPE standards; can be triangulated with other measures

Can be measured by pre/post and follow-up survey questions to track changes over time

Can be useful to evaluate using a survey since low satisfaction may create a barrier to implementing a novel approach and high satisfaction may increase acceptance of new approach and facilitate implementation

Uses standardized questions that can be tracked over time; additional questions could be added to address study objectives; could include asking open-ended questions that would allow for qualitative thematic analysis

Can be administered pre/post and at followup to track changes over time; quiz questions can be aligned with research objectives
May not include feedback to students, which could result in students' viewing as busy work; if the students' self-assessments are evaluated, it may require a large number of faculty to grade them; needs standardized rubric to ensure consistency among multiple graders or multiple students self-assessing; need for training of graders for consistent use of rubric; students may be weak at self-assessing

Perceptions or confidence as measures alone do not ensure attainment of knowledge or skills; students may be weak at self-assessing; perceptions do not signify that learning occurred

Can be confounded by faculty personality or grading outcomes; students can be biased against new or novel approaches to teaching or assessment; could be confounded by elective or required course; does not imply learning occurred

Can be impacted by low response rates, which could affect generalizability across all students; can suffer from gender bias; students responses can be influenced by timing of collection (eg, if given at completion of final exam, results could be focused on final exam vs. course); could be confounded by rewards for completion which could positively inflate results

Outcome may be confounded by students studying or preparing for quiz; high quiz grade does not imply long term retention, transfer or application; may impact long-term retention because of the testing effect 
Quiz, Surprise ${ }^{40,41}$

Examination

Cases $^{42}$

$\mathrm{TBL}^{43,44}$

Course Grades ${ }^{45}$

$\mathrm{PCOA}^{46,47}$
Can be administered pre/post and at followup to track changes over time; quiz questions can be aligned with research objectives; element of surprise may control for studying/preparing for the quiz

Can be measured pre/post and at follow-up to track changes over time; exam questions can be aligned with research objectives; includes more content and questions than a quiz which may give more insight into knowledge

Case questions with either open-ended or multiple-choice question prompts allow for assessment of higher-level knowledge application

IRAT/TRATs allow for low-level knowledge assessment and the additional use of case questions with multiple-choice question prompts allows for assessment of higher-level knowledge application and ability to use evidence to justify solutions

Can track longitudinal changes over multiple cohorts/years of students; course objectives can be aligned with program learning outcomes

Can benchmark across years in a program and across institutions; PCOA score report gives detailed feedback by area and topic;
When conducted right after exposure, long-term retention, transfer, or application is not ensured; high quiz grade does not imply long term retention, transfer or application; may impact long-term retention because of the testing effect

If longitudinally tracking a course over multiple years, course changes such as new faculty, new content, new questions, updated learning objectives may make it difficult to compare across years; high exam grade does not imply long term retention, transfer or application; when used as only outcome, conclusions are limited because students should gain knowledge as a result of being in the course

Open-ended case question prompts may not be clear to the learner, resulting in incorrect answers due to clarity not lack of knowledge; case question writers may be overconfident that their question(s) were written at a high level; case specificity effect can occur, implying that success on any given case is specific to that case

Case questions are answered as a team, which prevent tracking of individual performance data; case question writers may be overconfident that their question(s) were written at a high level; case specificity effect can occur, implying that success on any given case is specific to that case

Can be confounded by participation grades or grade inflation; comparing course grades over multiple years may be difficult due to changes to grade components, course requirements, points distribution across years, and/or different course coordinators; high course grade does not imply long term retention, transfer, or application

Limited number of questions per topic may result in a "case specificity" effect where students may have content knowledge but get the related PCOA questions 
does not require study time for students

Behavior

OSCE (performance

based) ${ }^{48}$

Experiential Learning

(IPPE/APPE) ${ }^{49}$

Results

Entrustable Professional Activities ${ }^{50}$

\section{NAPLEX/MPJE ${ }^{51}$}

Performance in practice 52,53
Authentic assessment method to assess both behaviors and knowledge; objective grading with standardized rubrics; confidence translatable to practice

Authentic assessment method to assess both behaviors and knowledge; indicates if knowledge is transferable to practice

Standardized language to define actions; can align study objectives to these measures

Required of all graduates for licensure; developed by experts to assess knowledge of practice-ready examinees

Ultimate outcome of training; can assess impact on patient outcomes wrong; high PCOA score does not imply long term retention depending on when administered, transfer or application of knowledge; PCOA measures knowledge not skills; PCOA blueprint may not be aligned with the study's research objectives; poor performance may be confounded by exam stress, test length, unfamiliar testing software, etc.; could be influenced by testing practices of the institution ("prep" exam, incentives, etc.)

May be a difficult assessment method to use because of extensive training required of case authors,

standardized participants, and assessors; which can be costly; could be confounded by exam logistics, student stress, and standardized participants

Interrater reliability can be difficult to achieve; generalized rubrics don't allow for specific feedback; diversity of experiences make data analysis challenging; lack of grade variation or possible grade inflation

Not consistently used across programs; generalized rubrics don't allow for specific feedback

Limited feedback provided to colleges/schools regarding graduate performance; limited feedback provided to examinees

Limited avenue for data collection; no standard tool for measurement of success in various practice settings 
Table 2. Problems and Solutions for Research Assessments, Tools, and Models

\begin{tabular}{lll}
\hline Methodology & Problem & Solution \\
\hline
\end{tabular}

Assessments

Pre-Post

Post only

Pre/Post/Long-term

Surveys, validated

Rubrics ${ }^{55}$

Psychological instruments
Only measuring before and after an intervention does not capture long-term retention.

Not capturing participants at baseline makes it difficult to evaluate improvement as a result of the intervention.

May lose participants to attrition especially if the follow-up is 1 year later or after participants graduate.

\section{Validation is required.}

If you change them, you have to validate them again.

Rubrics may not be able to assess every research construct.

Assessors may interpret rubric differently.

Rubric may not be validated.

Instrument may not fit study objectives.

Cost can be prohibitive.
Add an additional long-term follow up measurement after a sufficient length of time has passed.

Add a baseline assessment.

If the window for capturing participants at baseline has passed, consider assessing a different year of participants, but make sure to analyze both groups to ensure they are similar.

Ensure you tell participants about the plans for follow-up and ask them to provide current contact information. Consider shortening the long-term time window, if possible, to increase access to participants.

Consider Kane's framework for validation - scoring, generalization, extrapolation, and implications.

Gain input from multiple sources on rubric creation.

Train assessors on how to use the rubric to increase reliability.

Validate rubric using different evaluators or institutions.

Review and report statistics regarding rubric performance.

Contact authors for collaboration and possible discounts.

Explore options for grant funding. 
Models

Cross Over/Within Challenging to do in a

Subjects ${ }^{41}$

Between Subjects

classroom. confounder.
Topic difficulty is a potential

Can be difficult to ensure that the two cohorts are equivalent

May take a long time to collect data if using the same class in different years.
Use a block design to control for nuisance factors, such as topic difficulty, that detract from the variable being measured.

Assess baseline skills to know if there are substantial differences in baseline knowledge or skills.

Could use different sections of the same course, if available. 
Table 3. Different Types of Available Hierarchical Models Across Knowledge, Skills, and Attitudes
Cognitive domain
(Knowledge)
Affective domain
(Attitudes)
Psychomotor domain
(Skills)

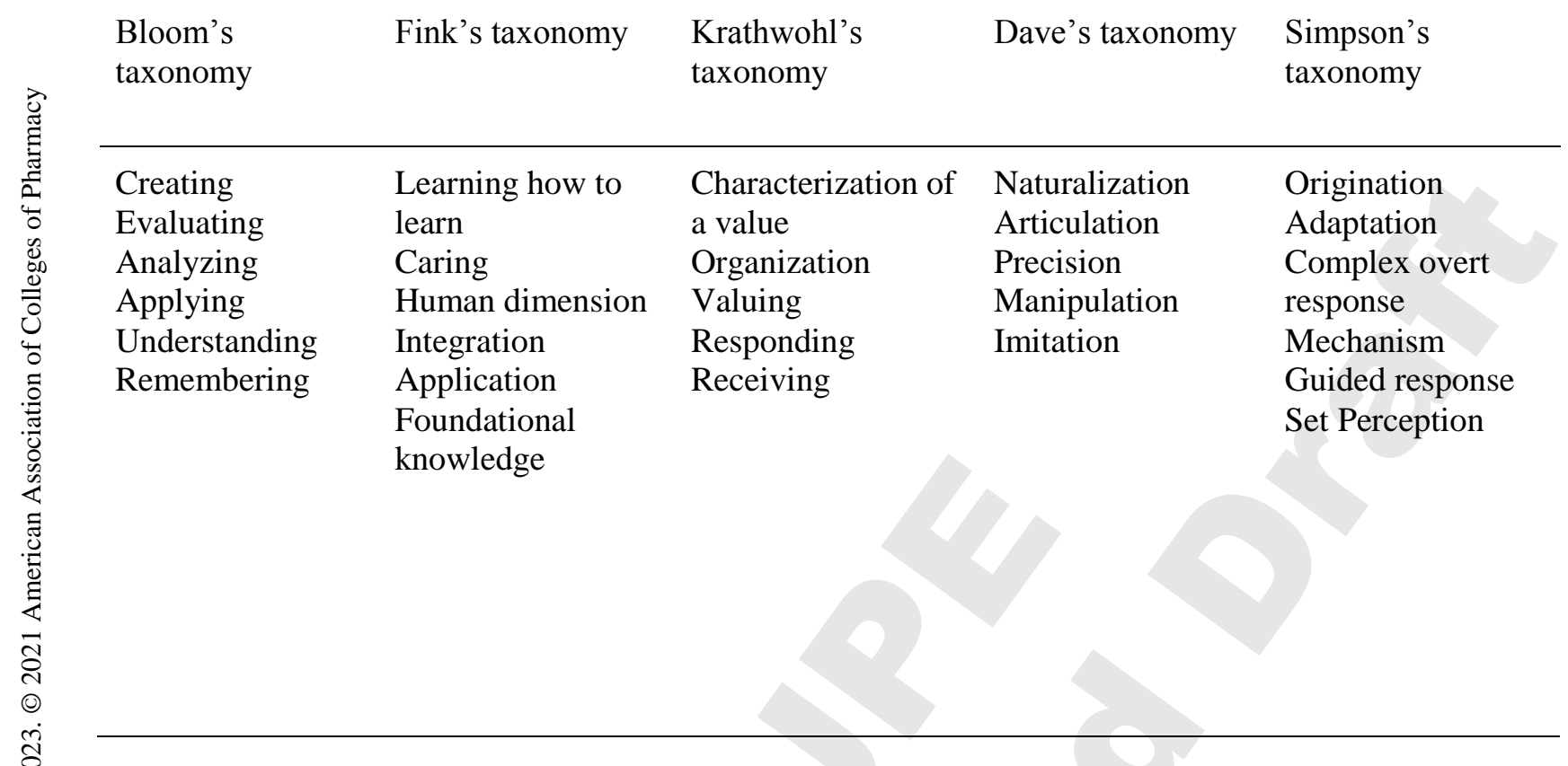


Table 4. Four Major Types of Mixed Methods Designs

Type

Explanatory sequential

Exploratory sequential

Parallel

Nested

\section{Process}

Quantitative data collected and analyzed first, then qualitative data collected and analyzed in an effort to help explain quantitative findings

Qualitative data collected and analyzed first, then quantitative data collected and used to empirically test findings

Qualitative and quantitative data collected and analyzed concurrently

One research dimension is primary design with other dimension embedded to answer a complementary question 